\title{
Integrating Psychiatric Services into Comprehensive Dementia Care in the Community
}

\author{
Hiroto Ito ${ }^{1}$, Hideyuki Hattori' ${ }^{2}$, Hiroaki Kazui ${ }^{3}$, Masamoto Taguchi ${ }^{4}$, Manabu Ikeda ${ }^{5}$ \\ ${ }^{1}$ Department of Social Psychiatry, National Institute of Mental Health, National Center of Neurology and \\ Psychiatry, Tokyo, Japan \\ ${ }^{2}$ National Center for Geriatrics and Gerontology, Aichi, Japan \\ ${ }^{3}$ Department of Psychiatry, Osaka University Graduate School of Medicine, Osaka, Japan \\ ${ }^{4}$ Ogaki Hospital, Gifu, Japan \\ ${ }^{5}$ Department of Neuropsychiatry, Faculty of Life Sciences, Kumamoto University, Kumamoto, Japan \\ Email: ${ }^{*}$ ItoHiroto@ncnp.go.jp
}

Received 5 February 2015; accepted 1 March 2015; published 4 March 2015

Copyright (C) 2015 by authors and Scientific Research Publishing Inc.

This work is licensed under the Creative Commons Attribution International License (CC BY).

http://creativecommons.org/licenses/by/4.0/

(c) (i) Open Access

\begin{abstract}
Purpose: This study was conducted to clarify the utility of patient-held records as an integrated care approach for patients with dementia in the community. Method: We analyzed the familyheld/patient-held records of patients with dementia in the community. The inclusion criteria in the study were as follows: 1) patient-held/family member-held records of patients with dementia in the community; 2) patient-held records designed to share information across different professionals, direct-care staff members, and local government staff; and 3) the continuous participation of psychiatrists in the development and use of the patient-held records. Results: We identified eight sets of family-held/patient-held records in Japanese communities of various sizes, all of which were aimed at integrating information from various services, including information provided by medical and psychiatric professionals to the family and patient. Innovative tools have been available in the areas of the hopes and preferences of the patient, medication and monitoring, sharing information, and the use of information technology. Conclusion and Discussion: Familyheld/patient-held records have potential as a tool to enhance the integrated care of people with dementia in the community.
\end{abstract}

\section{Keywords}

Dementia, Integrated Care, Patient-Held Medical Record, Psychiatry

\footnotetext{
"Corresponding author.
}

How to cite this paper: Ito, H., Hattori, H., Kazui, H., Taguchi, M. and Ikeda, M. (2015) Integrating Psychiatric Services into Comprehensive Dementia Care in the Community. Open Journal of Psychiatry, 5, 129-136. 


\section{Introduction}

Dementia has become a major public health concern worldwide due to the aging populations in many countries [1]. Among the developed countries, Japan is facing a "super-aging" society with an increasing number of elderly individuals [2]. As the number of aged people increases, so does the number of people with dementia. According to the results of a multicentre epidemiological study in Japan, the numbers (prevalence per population) of individuals aged 65 and over with dementia and mild cognitive impairment were 4.6 million (15\%) and 4.0 million (13\%) respectively [3]. In brief, in 2013, one-fourth of the people of Japan were aged 65 and over (with a projected estimate of $40.5 \%$ in 2055), and one-fourth of the people aged 65 and older (with a projected estimate of one-tenth of the total population in 2055) were estimated to be cognitively impaired.

Integrated care is an essential concept for caring for people with dementia in the community. People with dementia often suffer from multiple chronic conditions, including diabetes [4], stroke [5] and heart disease such as atrial fibrillation [6], and thus they need to receive multiple forms of treatment from many professionals. It is also necessary for them to receive nonmedical community social services.

Family members and informal carers may play important roles in integrating these multiple services to share information about the diagnosis and individual treatment plans for people with dementia in their community. The importance of family members' roles in transition from one care service to another has been highlighted [7] [8].

Patient-held medical records have been used as a tool to share care information with patients and professionals [9] [10]. However, people with cognitive impairment often have difficulty in understanding and remembering to use their patient-held records, and the utility of these records for family member and informal caregivers is not clear.

This study was conducted to clarify the utility of patient-held or family-held care records as an integrated care approach for patients with dementia in the community.

\section{Method}

\subsection{Materials}

We analyzed the family-held/patient-held records of patients with dementia in communities that meet our criteria in Japan. Since psychiatry is part of dementia care in Japan, we include only family-held/patient-held records that are developed in collaboration with psychiatric services. Although dementia care comprises more than psychiatry alone, it is necessary to consult with a psychiatrist when behavioural and psychological symptoms of dementia appear. The inclusion criteria in the study were as follows: 1 ) patient-/family member-held records for the individual with dementia; 2) the patient-held care records were designed to share information across professionals, direct-care staff members, and local government staff; and 3) psychiatrists continuously participated in the development and use of the patient-held records of patients.

\subsection{Search Strategy}

In Japan, the government's health policy promotes the use of family-held/patient-held records of patients with dementia in each prefecture based on the Regional Health Care Strategic Plan implemented in 2013 [11]. The National Center of Neurology and Psychiatry, a government-funded national institute, helps local governments and healthcare organizations develop and use family-held/patient-held records of patients with dementia in the community. The National Center of Neurology and Psychiatry created a website with materials that were easy to access and download regarding current government health policy, emphasizing the importance of family-held/ patient-held records of patients with dementia. Using this website, we encouraged individuals to send us familyheld/patient-held records of patients with dementia in each community, for sharing model activities with staff of other communities.

Between 2012 and 2014, we also conducted workshops on the Regional Health Care Strategic Plan with staff from local governments and healthcare organizations, in collaboration with the national-level government and that of Nagano Prefecture. Participants brought their family-held/patient-held records of patients with dementia to the workshop, the records was described to the participants.

In addition to the nationwide systematic search strategy, we searched for articles in academic communities between 2012 and 2014 in Japan to find family-held/patient-held records of patients with dementia. 


\subsection{Analysis of the Contents of Family-Held/Patient-Held Records of Patients with Dementia}

After searching for family-held/patient-held records of patients with dementia in Japan, our research group shared and analyzed all records. We first broke down elements of each record and made a table of elements. Nine elements were categorized based on previous research [12]-[16] on family-held/patient-held records of patients as follows: 1) patient profile [13] [14]; 2) hopes/preferences; 3) daily planner (e.g. appointments) [14][16]; (4) resources [13] [15] [16]; 5) diagnosis and treatment [14]-[16]; 6) monitoring [14]; 7) exchange notebook with multiple services [14]; 8) referral; and 9) use of information technology. The elements of hopes/preferences, referral, and use of information technology were included because they were regarded as essential to the integration of care services for people with dementia in the community.

We asked staff members who used family-held/patient-held records of patients with dementia in each community to provide case descriptions of these records.

\section{Results}

\section{Overview}

Eight sets of family-held/patient-held records of patients with dementia met the criteria in this study. Figure 1 shows the coversheet of the records and characteristics of each of the eight communities. The populations in these communities ranged from 55,000 in Arao City to 764,000 in Tokushima Prefecture. The coversheets were unique, and Arao City (Kumamoto), Kawanishi City (Hyōgo), the Jyoetsu area (Niigata), and the Nakasorachi area (Hokkaido) also used local mascots.

The contents of each family-held/patient-held record are shown in Table 1. All records were A5-sized, and four of these were presented in binders. The first set of family-held/patient-held records (Gifu) was developed primarily in 2011 by Ogaki Hospital. The records focused on the diagnosis, treatment and monitoring of symptoms, and was distributed to hospitals that were members of the Japanese Association of Psychiatric Hospitals. The Ogaki City model is currently in the feasibility study stage, aimed at connecting the family-held/patientheld records and information technology to allow information to be shared in a more flexible way. For the first (Gifu) and third (Kumamoto) sets of family-held/patient-held records of patients, there is a plan to use three standardized scales for monitoring cognitive impairment, instrumental activities of daily living, and behavioural and psychological symptoms of dementia using information technology.

The second set of family-held/patient-held records (Nagano) was developed in 2012 during a multicentre, multidisciplinary meeting including Saku Hospital, Saku Public Health Center, and Ueda City in the area. Ueda City (population 157,000) officially distributes these records to resident family members/patients who come to the city office.

The third set of family-held/patient-held records (Kumamoto) was developed in 2012 by the Department of Neuropsychiatry at Kumamoto University. The department took a central part in dementia care planning in Ku

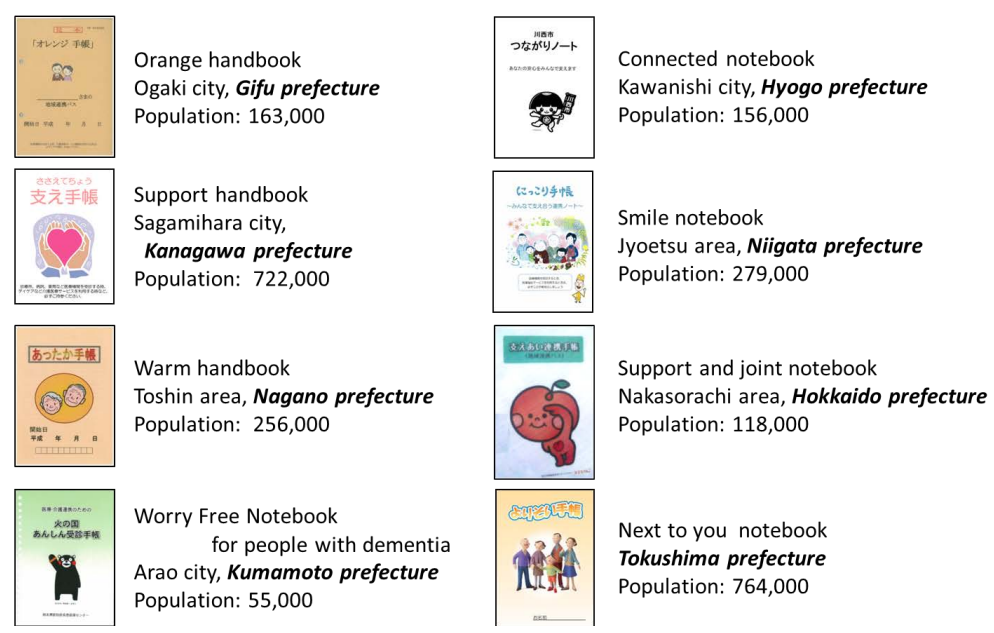

Figure 1.Coversheets of family-held/patient-held records of patients. 
Table 1. Contents of family-held/patient-held records.

\begin{tabular}{|c|c|c|c|c|c|c|c|c|}
\hline & 1 & 2 & 3 & 4 & 5 & 6 & 7 & 8 \\
\hline Prefecture & Gifu & Nagano & Kumamoto & Hyōgo & Niigata & Kanagawa & Hokkaido & Tokushima \\
\hline Year (first version) & 2011 & 2012 & 2012 & 2013 & 2013 & 2013 & 2013 & 2014 \\
\hline \multirow{3}{*}{$\begin{array}{l}\text { Size } \\
\text { Binder } \\
\text { Patient profile }\end{array}$} & A5 & A5 & A5 & A5 & A5 & A5 & A5 & A5 \\
\hline & & & $x$ & $x$ & $x$ & $x$ & & \\
\hline & $x$ & $x$ & $x$ & $x$ & $x$ & & $x$ & $x$ \\
\hline Hope/preference & & $x$ & & $x$ & $x x$ & $x$ & $x$ & $x$ \\
\hline Daily planner (appointment) & & $x$ & $x x$ & $x x$ & $x x$ & $x x$ & & \\
\hline Resources & $x$ & $x$ & $x$ & $x$ & $x$ & $x$ & $x$ & $x$ \\
\hline $\begin{array}{l}\text { Diagnosis and treatment } \\
\text { (dementia) }\end{array}$ & $x$ & $x$ & $x$ & $x$ & $x$ & $x$ & $x$ & $x$ \\
\hline $\begin{array}{l}\text { Diagnosis and treatment } \\
\text { (other diseases) }\end{array}$ & $x$ & & $x x$ & $x$ & $x$ & $x$ & $x$ & $x$ \\
\hline Monitoring & $x x$ & $x$ & $x x$ & $x$ & $x$ & $x x$ & $x$ & \\
\hline $\begin{array}{l}\text { Exchange notebook with } \\
\text { multiple services }\end{array}$ & & $x$ & $x x$ & $x x$ & $x x$ & $x$ & $x$ & \\
\hline Referral & & & $x x$ & & & & $x x$ & $x x$ \\
\hline Use of information technology & $x x$ & & $x$ & & & & & \\
\hline
\end{tabular}

$\times$ : The element is included. $x \times$ : The included element is evaluated as rich and innovative.

mamoto Prefecture. Family-held/patient-held records are distributed to all areas in Kumamoto Prefecture. This third set of records is focused on the four components of schedule, diagnosis and treatment, monitoring, and referral.

The referral formats are designed to be reimbursed by the fee schedule of the national insurance system. Arao City, one of 10 catchment areas in Kumamoto Prefecture, actively participates in using the third set of records. The black bear mascot, "Kuma-mon” (kuma means "bear” in Japanese), is a formal brand of the Kumamoto local government. Residents and staff of Kumamoto Prefecture are freely permitted to use the Kuma-mon after registration. This set of records is shared not only with staff of dementia care services, but also with dental care practitioners. In Arao City, one dentist is responsible for dental care for people with dementia in the community in addition to the patients who visit her office. She visits residential facilities and hospitals, and even visits the homes of people with dementia. She notes essential information regarding dental care in the family-held/patient-held records. A psychiatrist asked this dentist for patients' dental care records. Challenges regarding the personal and diagnostic information to be shared may be encountered; for example, sharing diagnostic information sometimes results in conflicts among various healthcare providers.

In the third set of family-held/patient-held records of patients (Kumamoto Prefecture), a unique approach was developed to simplify prescriptions from multiple physicians. In this set of records, it was suggested that each physician entered information in a prescription list sheet. Items on the list include drug name, usage, the start date of the prescription, the target of the treatment, and the name of healthcare organization. An example of the sheet is as follows:

Donepezil hydrochloride, 5 mg after breakfast, since February 10, 2014, improving forgetfulness, clinic A.

The fourth set of family-held/patient-held records (Hyōgo) was originally developed by the Department of Psychiatry at Osaka University and implemented in Kawanishi City. The records were designed primarily to share information on patient care with all multicentre staff and family members. Staff members of Kawanishi City take a central role to using the records in collaboration with the Kawanishi Medical Association. In Kawanishi City, there is a unique practice whereby family members participate in a training program to use the records every month. The program facilitates information sharing not only for professionals but also with family members. The record functions as a source of important information to change prescriptions. In one case, the staff of an elder day care service noted an individual's dizziness and a high risk of falling after the administration of newly prescribed benzodiazepine. After checking the information in the records, the physician changed the individual's prescription from the benzodiazepine to another drug. 
Another example was recorded with regard to the behavioural and psychological symptoms of patients with dementia. Public sector staff noted in the family-held/patient-held records that a family member reported the emergence of behavioural disturbances in persons with dementia. The physician checked the documentation and gave these patients an additional, new medication, which resulted in improvement in the behavioural problems.

The fifth set of family-held/patient-held records (Niigata Prefecture) was originally developed by a psychiatric hospital in the area. The records are designed to focus on sharing the patient's hopes and preferences in regard to their treatment and lifestyle. The record is summarized in the first person. The sections in these records include the following: 1) the patient's own preferences about where he or she wanted to live; 2) the patient's personal history and preferences; and 3) advance directives for medical decisions. This section sheet is revised periodically if necessary.

The sixth set of family-held/patient-held records (Kanagawa Prefecture) was developed in 2013 based on the experience of keeping records on depression by the Department of Psychiatry at Kitasato University East Hospital (2011). The records are unique in including monitoring the family/caregiver burden of caring for patients with dementia.

The seventh set of family-held/patient-held records (Hokkaido Prefecture) was originally developed at Sunagawa City Medical Centre, and currently an independent non-profit organization is responsible for the distribution of the records. The records are primarily designed for referrals among services. An apple (Supporter) is the formal mascot of Sunagawa City.

The eighth set of family-held/patient-held records (Tokushima Prefecture) is the formal records of the prefecture. The prefecture started distributing the records in 2014.

\section{Discussion}

The results of our analysis showed that family-held/patient-held medical records for patients with dementia in the community are widespread in Japan. All of the integrated care programs being used are aimed at integrating information from various services, including medical and psychiatric professionals, to give to the family and patient. Innovative tools have been developed in the areas of the hopes/preferences of the patient, medication and monitoring, sharing information, and the use of information technology. In addition, we also found that familyheld/patient-held records of patients were designed using local mascots.

The aims of the integrated care programs were reducing fragmentation and improving continuity and coordination of care [17]. Based on a systematic review of integrated care programs, Ouwens et al. (2005) categorized seven components of integrated care programs as follows: 1) self-management support and patient education; 2) clinical follow-up; 3) case management; 4) multidisciplinary patient care team; 5) multidisciplinary clinical pathway; 6) feedback, reminders and education for professionals; and 7) a supportive clinical information system and other additional requirements such as leadership [17]. The use of family-held/patient-held records of patients may primarily function as a multidisciplinary clinical pathway, and these records promote other components such as self-management support, clinical follow-up, case management, and a supportive clinical information system.

\subsection{Hopes/Preferences}

Respecting the hopes and preferences of each patient is a critical element in the enhancement of dementia patients' self-management. Some family-held/patient-held records include a sheet for the patient's hopes and preferences, including advance directives. Recently, the concept of decisional capacity has been changing from a categorical and exclusionary concept to a dimensional and inclusionary concept [18]. Professionals need to assess what type of support is needed by people with decision-making disabilities in order for them to be involved in decision making [18]. Family-held/patient-held records of patients with dementia also function as the documentation of patient hopes and preferences from a time when the patient had a better level of decisional capacity and less cognitive impairment [19].

\subsection{Follow-Up}

In the first (Gifu Prefecture) and third (Kumamoto Prefecture) sets of records, a follow-up plan is discussing using standardized scales: 1) The Mini-Mental State Examination (MMSE), which is a widely used questionnaire test to screen for cognitive impairment [20]; 2) Instrumental Activities of Daily Living (IADL) [21]; and 3) The 
Neuropsychiatric Inventory (NPI), developed by Cummings et al. (1994), which is a scale consisting of 10 subdomains of behavioural function that are used to assess dementia-related behavioural symptoms [22]. Sharing the scores of the scales helps monitor changes in the clinical symptoms of patients with dementia.

\subsection{Case Management}

Case management, or the explicit allocation of coordination tasks to an appointed individual [17], is a promising but costly component of integrated care programs. Some family-held/patient-held records of dementia patients alternatively function as part of case management in relation to symptom monitoring and revising care plan. Case descriptions of the third (Kumamoto Prefecture) and fourth (Hyōgo Prefecture) sets of family-held/patientheld records show a coordinating function in the prescribing of medication by each physician. The healthcare system in Japan does not have a formal gate-keeping system, which means that people in their communities do not have a formal (or mandated) general practitioner, and patients with multiple chronic conditions often receive multiple prescriptions from several physicians. Family-held/patient-held records of patients may contribute to improvements in sharing information about medication changes.

\subsection{Information Technology}

Information technology plays an important role in integrating care. A challenge of family-held/patient-held records of patients is how to share current information with multidisciplinary team members. This is important when a patient becomes sicker or unstable, when a patient shows non adherence, and when a patient drops out. If the family-held/patient-held records of a patient are connected to a cloud server in part, care staff can check the current status of the patient using documentation from other services. At the same time, there are a number of issues to be solved with regard to the use of information technology, including confidentiality, information to be shared, and the personnel who use the information technology. Gifu Prefecture, which produced the first set of family-held/patient-held records of patients, plans to produce information about the appropriate uses of information technology with these records, based on a feasibility study.

\subsection{Confidentiality}

Ideally, family-held/patient-held records could be integrated using a cloud storage system on computers. However, those who are concerned about protecting individual personal information are resistant to using a cloud storage system. In addition, personal identification numbers have not been integrated in the public system in Japan. Therefore, some areas have started to use information technology for family-held/patient-held records without including the name of the patient. Another unsolved challenge regards who shares what types of information for dementia care. The Personal Information Protection Law in Japan restricts access to personal information. It is necessary to set criteria for varying levels of sharing information, and the consents of family and patients to share their information in different care settings should be required.

In the Ogaki area, the first set of family-held/patient-held records of patients was assigned an anonymous 15digit identification number before being distributed to patients with dementia or their family members. Only staff members responsible for the direct care of the patient have access to the patient identification number table. The Ogaki area is now at the feasibility study stage, connecting the first set of family-held/patient-held records of patients and a database of cloud servers using the identification numbers. The database functions to share minimum patient information with direct care staff at multiple facilities, using three subsystems (monitoring, a social service network, and reminders) [23]. The monitoring information includes the results of assessments using the MMSE [20], IADL [21] and NPI [22], and adherence.

\subsection{Healthcare System}

It is surprising that family-held/patient-held records for people with dementia have been independently developed in local communities since 2011, because individuals with dementia have cognitive impairment and are often have difficulty in using patient-held records. There are three possible reasons for the community-level development, the first of which relates to the traditional family involvement in caring for patients in Asian countries [24]. Family members usually take responsibility for the informal care of patients. The family-held/patient-held records of patients enable family members to actively participate in the medical care as a "team" caregiver.

Second, the healthcare system in Japan lacks gate-keeping tools to share medical information among staff 
members, patients, and family members because there is no formal gate-keeping system [25]. Countries such as Japan have difficulty in integrating medical information among team members of various organizations. Familyheld/patient-held records of patients enable the team members to share this information and function as a gatekeeping tool. Third, since 2013 the dementia care policy and related health policies in Japan have promoted the development of care pathways for people with dementia in the community [11]. The local government of each prefecture facilitates the development and use of the pathway. All family-held/patient-held records of patients in this study are categorized as care pathways.

\subsection{Limitations}

The present study has several limitations. First, though our research group conducted extensive investigations to gather family-held/patient-held records of patients for 2 years, other such records do exist. Second, most of the family-held/patient-held records of patients we found were at the stage of distribution to residents of each community. Although we show case examples, further research is necessary to assess the effectiveness of the familyheld/patient-held records for caring for patients with dementia in the community.

Despite the limitations, our results highlight the new challenges of family-held/patient-held records for people with dementia in their communities, and we have identified several innovative tools for integrating care. Japan has experience in reducing infant mortality using a child and maternal health handbook that is originally developed in 1947 [26]. The handbook is currently exported to more than 20 developing and developed countries [26]. In addition, since 2008 the care pathway in the community has been promoted for patients with cancer, stroke, acute myocardial infarction, and diabetes by Japan's government. The dementia care pathway was added in 2013 [11]. This trend may help care staff develop and use family-held/patient-held records of dementia patients in Japan. Family-held/patient-held records of patients have potential as a tool to integrate the care of people with dementia in the community.

\section{Conclusion}

Family-held/patient-held records for dementia patients have been developed in various local communities all over Japan, aimed at the integration of information from various services. Innovative tools have been available in the areas of hopes and preferences of the patient, medication and monitoring, sharing information, and the use of information technology. Family-held/patient-held records have potential as a tool to enhance the integrated care of people with dementia in the community.

\section{Acknowledgements}

This study was presented in part at the Asia-Pacific Economic Cooperation Workshop to Promote Innovative Collaborations in Mental Health on August 20, 2014 (Peking University). This study is being supported by Health and Labour Sciences Research Grant for Comprehensive Research on Disability Health and Welfare from the Japanese Ministry of Health, Labour, and Welfare. We thank Drs. Yu Kawamuro, Tomohisa Ishikawa, Yohio Yamanouchi, Hitoshi Miyaoka, Satru Oishi, and Ms. Yumiko Shimomura for providing valuable comments and information. We also thank Ms. Yumi Ohmori for her helpful assistance.

\section{References}

[1] Reitz, C., Brayne, C. and Mayeux, R. (2011) Epidemiology of Alzheimer Disease. Nature Reviews Neurology, 7, 137152. http://dx.doi.org/10.1038/nrneurol.2011.2

[2] Kaneko, R., Ishikawa, A., Ishii, F., Sasai, T., Iwasawa, M., Mita, F., et al. (2008) Population Projections for Japan: 2006-2055 Outline of Results, Methods, and Assumptions. The Japanese Journal of Population, 6, 76-114. http://www.ipss.go.jp/webj-ad/webjournal.files/population/2008_4/05population.pdf.

[3] Asada, T. (2014) Prevalence of People with Dementia in City Area and Care for Impairment in Daily Living. Final Report of Health and Labor Sciences Research Grant. http://www.tsukuba-psychiatry.com/wp-content/uploads/2013/06/H24Report Part1.pdf.

[4] Cheng, G., Huang, C., Deng, H. and Wang, H.. (2012) Diabetes as a Risk Factor for Dementia and Mild Cognitive Impairment: A Meta-Analysis of Longitudinal Studies. Internal Medicine Journal, 42, 484-491. http://dx.doi.org/10.1111/j.1445-5994.2012.02758.x

[5] Pendlebury, S.T. and Rothwell, P.M. (2009) Prevalence, Incidence, and Factors Associated with Pre-Stroke and Post- 
Stroke Dementia: A Systematic Review and Meta-Analysis. The Lancet Neurology, 8, 1006-1018. http://dx.doi.org/10.1016/S1474-4422(09)70236-4

[6] Santangeli, P., Di Biase, L., Bai, R., Mohanty, S., Pump, A., Brantes, M.C., et al. (2012) Atrial Fibrillation and the Risk of Incident Dementia: A Meta-Analysis. Heart Rhythm, 9, 1761-1768. http://dx.doi.org/10.1016/j.hrthm.2012.07.026

[7] Coleman, E.A., Smith, J.D., Frank, J.C., Min, S.-J., Parry, C. and Kramer, A.M. (2004) Preparing Patients and Caregivers to Participate in Care Delivered across Settings: The Care Transitions Intervention. Journal of the American Geriatrics Society, 52, 1817-1825. http://dx.doi.org/10.1111/j.1532-5415.2004.52504.x

[8] Elliott, J., Forbes, D., Chesworth, B.M., Ceci, C. and Stolee, P. (2014) Information Sharing with Rural Family Caregivers during Care Transitions of Hip Fracture Patients. International Journal of Integrated Care, 14, e018.

[9] Ko, H., Turner, T., Jones, C. and Hill, C. (2010) Patient-Held Medical Records for Patients with Chronic Disease: A Systematic Review. Quality and Safety in Health Care, 19, e41. http://www.ncbi.nlm.nih.gov/pubmed/?term=Ko\%2C+H.\%2C+Turner\%2C+T.\%2C+Jones\%2C+C.+and+Hill\%2C+C. $+(2010)+$ Patient-Held+Medical+Records+for+Patients+with+Chronic+Disease\%3A+A+Systematic+Review.+Quality +and+Safety+in+Health+Care $\% 2 \mathrm{C}+19 \% 2 \mathrm{C}$

[10] Gysels, M., Richardson, A. and Higginson, I.J. (2007) Does the Patient-Held Record Improve Continuity and Related Outcomes in Cancer Care: A Systematic Review. Health Expectations, 10, 75-91. http://dx.doi.org/10.1111/j.1369-7625.2006.00415.x

[11] Ito, H., Frank, R.G., Nakatani, Y. and Fukuda, Y. (2013) Mental Health Care Reforms in Asia: The Regional Health Care Strategic Plan: The Growing Impact of Mental Disorder in Japan. Psychiatric Services, 64, 617-619. http://dx.doi.org/10.1176/appi.ps.201200518

[12] Farrelly, S., Brown, G.E., Flach, C., Barley, E., Laugharne, R. and Henderson, C. (2013) User-Held Personalised Information for Routine Care of People with Severe Mental Illness. Cochrane Database of Systematic Reviews, 10, Article ID: CD001711. http://dx.doi.org/10.1002/14651858.CD001711.pub2

[13] Brunero, S., Lamont, S., Myrtle, L. and Fairbrother, G. (2008) The Blue Card: A Hand-Held Health Record Card for Mental Health Consumers with Comorbid Physical Health Risk. Australasian Psychiatry, 16, 238-243. http://dx.doi.org/10.1080/10398560801979222

[14] Lester, H., Allan, T., Wilson, S., Jowett, S. and Roberts, L. (2003) A Cluster Randomized Controlled Trial of PatientHeld Medical Records for People with Schizophrenia Receiving Shared Care. British Journal of General Practice, 53, 197-203.

[15] Stafford, A. and Hannigan, B. (1997) Client-Held Records in Community Mental Health. Nursing Times, 93, 50-51.

[16] Warner, J.P., King, M., Blizard, R., Mcclenahan, Z. and Tang, S. (2000) Patient-Held Shared Care Records for Individuals with Mental Illness. British Journal of Psychiatry, 177, 319-324. http://dx.doi.org/10.1192/bjp.177.4.319

[17] Ouwens, M., Wollersheim, H., Hermens, R., Hulscher, M. and Grol, R. (2005) Integrated Care Programmes for Chronically Ill Patients: A Review of Systematic Reviews. International Journal for Quality in Health Care, 17, 141-146. http://dx.doi.org/10.1093/intqhc/mzi016

[18] Peisah, C., Sorinmad, O.A., Mitchell, L. and Hertogh, C.M.P.M. (2013) Decisional Capacity: Toward an Inclusionary Approach. International Psychogeriatrics, 25, 1571-1579. http://dx.doi.org/10.1017/S1041610213001014

[19] Campbell, L.A. and Kisely, S.R. (2009) Advance Treatment Directives for People with Severe Mental Illness. Cochrane Database of Systematic Reviews, 1, Article ID: CD005963.

[20] Folstein, M.F., Folstein, S.E. and McHugh, P.R. (1975) “Mini-Mental State”. A Practical Method for Grading the Cognitive State of Patients for the Clinician. Journal of Psychiatric Research, 12, 189-198. http://dx.doi.org/10.1016/0022-3956(75)90026-6

[21] Lawton, M.P. and Brody, E.M. (1969) Assessment of Older People: Self-Maintaining and Instrumental Activities of Daily Living. The Gerontologist, 9, 179-186. http://dx.doi.org/10.1093/geront/9.3_Part_1.179

[22] Cummings, J., Mega, M., Gray, K., Rosenberg-Thompson, S., Carusi, D.A. and Gornbein, J. (1994) The Neuropsychiatric Inventory: Comprehensive Assessment of Psychopathology in Dementia. Neurology, 44, 2308-2314. http://dx.doi.org/10.1212/WNL.44.12.2308

[23] Ito, H., Sugiura, S., Noda, H. and Higuchi, T. (2013) Creating an Online Patient Follow-Up System. Shakai Hoken Jyunpo, 2531, 10-14. (In Japanese) http://mhcnp.jp/pdf/130513_syakaiHokenJunpo.pdf

[24] Ito, H., Setoya, Y. and Suzuki, Y. (2012) Lessons Learned in Developing Community Mental Health Care in East and South East Asia. World Psychiatry, 11, 186-190.

[25] OECD (2010) Health Care Systems: Getting More Value for Money. OECD Economics Department Policy Notes, No. 2. http://www.oecd.org/eco/growth/46508904.pdf

[26] Nakamura, Y. (2010) Maternal and Child Health Handbook in Japan. JMAJ: Japan Medical Association Journal, 53, 259-265. https://www.med.or.jp/english/journal/pdf/2010_04/259_265.pdf 